Beck, I. F. (1947). Social Work, 4, 46.

Beck, I. F., Gardner, F. V., and Witts, L. J. (1947). British fournal of Social Medicine, 1,197

Brown, G. M., and Carling, F. C. (1945). British Medical fournal, 1, 478.

Davidson, L. S. P., Fullerton, H. W., and Campbell, R. M. (1935). British Medical fournal, 2, 195

Donald, K. W. (1971). Proceedings of the Royal Society of Medicine, 64, 303.

Dragsted, C. A. (1962). Perspectives in Biology and Medicine, 5, 364.

Gardner, F., and Witts, L. J. (1946). Lancet, 2, 392.

Halliday, J. L. (1949). Psychological Medicine. London, Heinemann.

Lewis, T. (1933). British Medical fournal, 2, 717.

McKeown, T. (1965). Medicine in Modern Society, London, Allen and Unwin.
Price, D. J. de Solla (1963). Little Science, Big Science. New York, Columbia University Press.

Peart, W. S. (1970). Lancet, 1, 401

Report of the Inter-Departmental Committee on Medical Schools (Goodenough Committee) (1944). London, H.M.S.O.

Royal Commission on University Education in London (1913). London H.M.S.O.

Witts, L. J. (editor). (1964). Medical Surveys and Clinical Trials, 2nd ed. London, Oxford University Press.

Wood, F. P. (1966). Transactions of the Association of American Physicians, $79,1$.

Wyngaarden, J. B. (1971). Archives of Internal Medicine, 127, 80.

\title{
Prognostic Implications of Electroencephalographic Findings of Hypsarrhythmia in First Year of Life
}

\author{
ETTA FRIEDMAN，G. PAMPIGLIONE
}

British Medical fournal, 1971, 4, 323-325

\section{Summary}

One hundred and five children who had shown the electroencephalographic (E.E.G.) features of hypsarrhythmia in the first year of life (1956-62) were assessed in 1969 in respect of death and mental development. Irrespective of the presenting symptomatology, and to some extent irrespective of therapy, mortality in the group was of the order of one in four (mostly before the age of 3 years) and the incidence of mental subnormality in the survivors was $77 \%$. Only 18 children attained fairly normal standards of mental development and could attend ordinary schools. It seems that whatever the clinical picture at the time, the presence of hypsarrhythmia in the E.E.G. of an infant is a physical sign of grave prognostic implications.

\section{Introduction}

In clinical practice electroencephalography (E.E.G.) provides information on some aspects of cerebral function in the course of an illness. Most E.E.G. features, like other physical signs in medicine, can be interpreted only in the context of the patient's clinical picture at the time. Some E.E.G. findings, however, as with certain other laboratory investigations, may carry a special diagnostic or prognostic significance whatever the initial clinical circumstances, being found only in particular pathological conditions. Such E.E.G. findings include, for example, the periodic complexes in subacute sclerosing panencephalitis, the repetitive discharges of Jacob-Creutzfeldt disease, or some of the patterns in barbiturate poisoning.

Hypsarrhythmia is the name given by Gibbs and Gibbs (1952) to a gross E.E.G. abnormality never reported in any series of normal control children. Children with hypsarrhythmic E.E.G.s are usually below the age of 2 years, often under 12 months, and may be suffering from poorly understood disorders affecting the brain. Clinically, they present with a variety of symptoms, often, but not invariably, including seizures of some kind. While the syndrome of infantile spasms is known to be commonly accompanied by the E.E.G. findings of hypsarrhythmia, it is not often appreciated that hypsarrythmia

\footnotetext{
Department of Neurophysiology, The Hospital for Sick Children, Great Ormond Street, London W.C.1

ETTA FRIEDMAN, M.B., CH.B., Senior Registrar

G. PAMPIGLIONE, M.D., F.R.C.P., Physician in Charge
}

may be found in children without this syndrome, and even in the absence of seizures of any kind (Hess and Neuhaus, 1952). In the original work of Gibbs and Gibbs (1952) it was suggested that hypsarrhythmia - that is, a term describing only the E.E.G. features-was often associated with mental retardation. This view was also supported by the work of Samson-Dollfus (1959) on 15 children with hypsarrhythmic E.E.G.s and various clinical features.

The present survey was planned to assess the prognostic implications of the finding of hypsarrhythmia in the E.E.G.s of infants, irrespective of the presenting symptomatology. The outcome after several years was assessed in relation to survival and general intelligence.

\section{Subjects and Methods}

During the six years from December 1956 to December 1962, 894 children in their first year of life had E.E.G.s taken at the Hospital for Sick Children. The E.E.G.s of these infants were reviewed, and the features of hypsarrhythmia were found in 143 cases. The presenting clinical symptomatology and history showed a great deal of individual variation, though most of the babies had been referred for E.E.G. studies because of seizures of one or other kind. In a few children, however, no seizures had been reported by the time hypsarrhythmia had appeared.

The only two criteria for inclusion in the study were the age of the child (up to 1 year) at the time of the relevant E.E.G. and the features of hypsarrhythmia (see Fig.), defined as

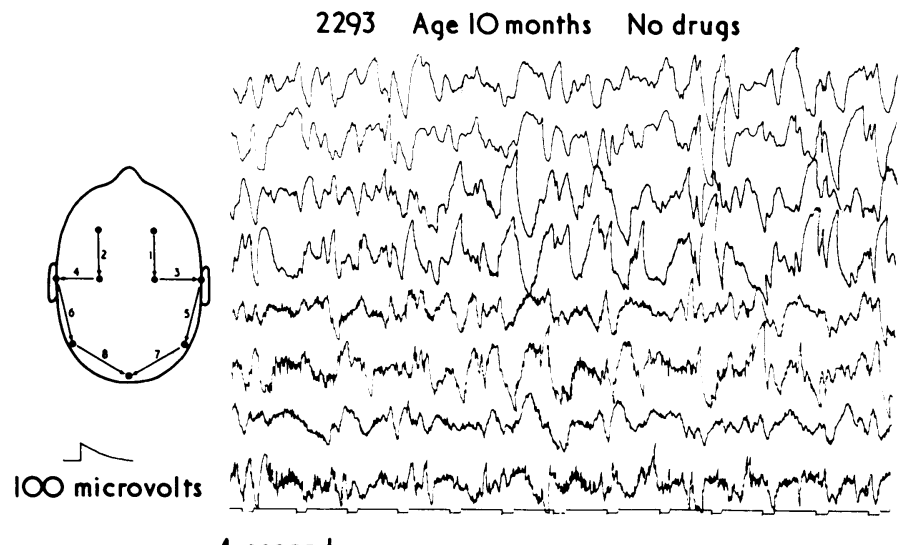

1 second

E.E.G. of child aged 10 months. Drugs had not been given. Calibration 100 microvolts. Time marker 1 second. 
follows: (1) predominant generalized, irregular activity at $1-5 \mathrm{c} / \mathrm{s}$ of at least 300 microvolts in amplitude and often considerably more; (2) spikes or sharp waves of the order of 100-1,000 microvolts with variable distribution and phase relationship, usually unaffected by photic stimulation but often increased during sleep; and (3) poverty of rhythmic activity appropriate to the child's age with only minor E.E.G. change after passive eye closure during wakefulness.

In 1969 the clinical notes were studied with a view to assessing the course of the illness and the developmental progress of each child. No adequate information was available in 38 children, but the remaining 105 had been followed up at our hospital for periods up to a maximum of 12 years, and form the basis of the present study. The E.E.G.s were taken with uniform techniques and electrode placement (Pampiglione, 1956) and repeated whenever possible.

\section{Results}

The outcome in the 105 children was established in relation to the latest information known up to December 1969 (see Table I). Of the 27 deaths, 25 occurred within two years of the date of the

TABLE I-Outcome in 105 Infants with Hypsarrhythmia

\begin{tabular}{|c|c|c|c|c|}
\hline \multirow{2}{*}{ Dead } & \multicolumn{2}{|c|}{ Retarded } & \multicolumn{2}{|c|}{ Normal (or Nearly Normal) } \\
\hline & $\begin{array}{c}\text { Severely } \\
\text { I.Q. } \leqslant 55\end{array}$ & $\begin{array}{l}\text { Moderately } \\
\text { I.Q. 56-70 }\end{array}$ & I.Q. 71-85 & I.Q. $86+$ \\
\hline 27 & 40 & 20 & 5 & 13 \\
\hline
\end{tabular}

hypsarrhythmic E.E.G.-that is, below the age of 3 yearsand the other two at $3 \frac{1}{2}$ and $6 \frac{1}{2}$ years of age respectively. The clinical "diagnoses" before death included a variety of conditions: four cases of suspected degenerative cerebral disorder, three with aminoaciduria, three with various cerebral malformations detected radiologically, three with hydrocephalus, one child with a congenital heart disease, one was a Mongol, one had a haemorrhagic condition, and one developed leukaemia. In six others a "diagnosis" of cerebral atrophy was supported by pneumoencephalography. In four children no diagnosis was made. Most of these children finally succumbed to bronchopneumonia or other infection. The diagnosis therefore was usually symptomatic and the underlying aetiology remained obscure. Postmortem examination of the brain was obtained in four cases, and in'four others a brain biopsy had been performed. In all these eight children the histological changes were those of "non-specific atrophy."

In the surviving children, the clinical diagnoses were also varied, and largely symptomatic. Of these 78 children, 60 were found to be mentally subnormal, the subnormality being severe in 40 with an I.Q. below 56 (often not measureable by standard tests), while in the remaining 20 it was moderate with I.Q.s of 56-70 (educationally subnormal (ESN) at school age). Seizures had become less prominent as a feature in most of the surviving children. In the group of 18 classified as "normal or nearly normal" (I.Q. 71 or above), three were still having occasional seizures when last seen, at $6,7 \frac{1}{2}$, and 9 years of age respectively. All these 18 children were attending normal schools though "special" teaching was required in five whose I.Q.s were in the 71-84 range.

In the present series 27 children with hypsarrhythmia did not have infantile spasms at any stage of their illness, though some other form of seizure had occurred. The outcome in this smaller group was even worse than in the larger group of children with infantile spasms (see Table II).

The period covered in this study spanned the introduction of corticotrophin or steroid treatment for infantile spasms which was heralded by Sorel and Dusaucy-Bauloye (1958). We were
TABLE II-Influence of Spasms on Outcome of 105 Infants with Hypsarrhythmia

\begin{tabular}{l|c|c|c|c}
\hline \multicolumn{1}{c|}{$\begin{array}{c}\text { Infantile } \\
\text { Spasms }\end{array}$} & $\begin{array}{c}\text { No. of } \\
\text { Infants }\end{array}$ & Dead & Retarded & $\begin{array}{c}\text { Normal } \\
\text { (or Nearly } \\
\text { Normal) }\end{array}$ \\
\hline $\begin{array}{l}\text { With } \\
\text { Without }\end{array}$ & 78 & $\begin{array}{c}16(20 \cdot 5 \%) \\
27\end{array}$ & $\begin{array}{l}46(59 \%) \\
14(52 \%)\end{array}$ & $\begin{array}{c}16(20 \cdot 5 \%) \\
2(7.5 \%)\end{array}$ \\
\hline
\end{tabular}

$\chi^{2}$ (trend) $=6.0 . P<0.05$.

TABLE III-Clinical Outcome of 105 Infants with Hypsarrhythmia. 1957-62

\begin{tabular}{|c|c|c|c|c|c|}
\hline $\begin{array}{l}\text { Steroids/ } \\
\text { Corticotrophin }\end{array}$ & $\begin{array}{l}\text { Total } \\
\text { No. }\end{array}$ & Dead & $\begin{array}{l}\text { Severely } \\
\text { Retarded }\end{array}$ & E.S.N. & $\begin{array}{l}\text { Normal } \\
\text { (or Nearly } \\
\text { Normal) }\end{array}$ \\
\hline $\begin{array}{l}\text { Not given } \\
\text { Given } \quad . .\end{array}$ & $\begin{array}{l}55 \\
50\end{array}$ & $\begin{array}{l}17(31 \%) \\
10(20 \%)\end{array}$ & $\begin{array}{l}25(46 \%) \\
16(32 \%)\end{array}$ & $\begin{array}{r}8(14 \%) \\
11(22 \%)\end{array}$ & $\begin{array}{c}5(9 \%) \\
13(26 \%)\end{array}$ \\
\hline
\end{tabular}

TABLE IV-Clinical Outcome of 78 Children with Infantile Spasms. 1957-62.

\begin{tabular}{|c|c|c|c|c|c|}
\hline $\begin{array}{l}\text { Steroids/ } \\
\text { Corticotrophin }\end{array}$ & No. & Dead & $\begin{array}{l}\text { Severely } \\
\text { Retarded }\end{array}$ & E.S.N. & $\begin{array}{l}\text { Normal } \\
\text { (or Nearly } \\
\text { Normal) }\end{array}$ \\
\hline $\begin{array}{l}\text { Given ... } \\
\text { Not given }\end{array}$ & $\begin{array}{l}49 \\
29\end{array}$ & $\begin{array}{r}10(20.5 \%) \\
6(20.5 \%)\end{array}$ & $\begin{array}{l}16(32.5 \%) \\
14(48.5 \%)\end{array}$ & $\begin{array}{c}11(22 \cdot 5 \%) \\
5(17 \%)\end{array}$ & $\begin{array}{c}12(24 \cdot 5 \%) \\
4(14 \%)\end{array}$ \\
\hline
\end{tabular}

$\chi^{2}$ (trend) $=1 \cdot 4$. Not significant.

therefore able to compare the outcome of a group of 50 children treated with corticotrophin or steroids with a group of 55 children not so treated. While the prognosis for both groups was poor (all with hypsarrhythmia, whatever the clinical picture), there seemed to be a trend for a better outcome in children treated than in those not treated with corticotrophin or steroids $(P<$ 0.01) (Table III). However, when only the children with the clinical picture of infantile spasms ( 78 in all) were considered the difference between treated and untreated cases was no longer significant (Table IV).

\section{Discussion}

It is generally agreed that the clinical syndrome of infantile spasms has a poor prognosis (for reviews of the literature see Gastaut et al., 1964; Jeavons and Bower, 1964; Chevrie et al., 1968; among others). The incidence of mental retardation in patients followed up for varying periods is high (Gibbs et al., 1954 ) with a death rate of up to $22 \%$ (Jeavons et al., 1970). Most of the studies in the literature, however, are based on children with infantile spasms in whom the E.E.G. findings were only a subsidiary concomitant of the clinical picture. Jeavons and Bower (1964), however, recognized the presence of hypsarrhythmia as an important loading factor against a good outcome in 62 children with infantile spasms.

Only a few authors have considered the possible primary significance of the E.E.G. findings of hypsarrhythmia apart from infantile spasms syndrome (Gibbs and Gibbs, 1952; RebufatDeschamps, 1958). Lombroso and Rose (1964) approached this viewpoint but their work was limited to the neonatal period. Burnett et al. (1958), in a complementary type of study, found that 27 of their children with infantile spasms and a normal E.E.G. before the age of 1 year had a substantially better outcome than the larger number of children with abnormal E.E.G.s.

Our studies are primarily based on the finding of hypsarrhythmia in the E.E.G.s of infants, whatever their clinical history or symptoms at the time. These children seem to have a high mortality rate $(26 \%)$ and a very high proportion of mental subnormality in the survivors $(77 \%$ ) whether or not they had infantile spasms, other seizures, or other clinical features. This poor outcome becomes even more striking if we compare our group of patients with the figures for the general population 
extracted from the Statistical Review for England and Wales, 1968 (Registrar General, 1970): the mortality in children between 1 month and 5 years of age is about $1: 1,000$ while in our group of children who had a hypsarrhythmic E.E.G. the figure is about $1: 4$.

According to educational psychologists, an accepted figure for children of school age with an I.Q. above 70 is about $97 \%$, while in our series only $23 \%$ of the surviving patients achieved this level. If we then consider $3 \%$ as an accepted figure for mentally subnormal children in the general population, the figure in our series is of the order of $77 \%$. These findings therefore suggest that the presence of a hypsarrhythmic E.E.G. in the first year of life, irrespective of the clinical symptomatology at the time and largely irrespective of therapy, carries grave prognostic implications in terms of incidence of mental subnormality and early death. Since not all infants with a severe neurological illness in the first year of life develop hypsarrhythmia in their E.E.G., it is tempting to suggest that the presence of hypsarrhythmia might indicate a special type, or group, of disorders as yet unidentified.

This work was partly supported by a grant from the ClarissaNorman Research Fund on Epilepsy and by the Joint Research
Board (Hospital for Sick Children and Institute of Child Health), both gratefully acknowledged.

\section{References}

Burnett, L. L., Gibbs, E. L., and Gibbs, F. A. (1958). Pediatrics, 21, 719. Chevrie, J.-J., Aicardi, J., St. Thieffry, S., Grison, D., and Missoffe, C. (1968). Archives francaises de pédiatrie, 25, 263

Gastaut, H., Roger, J., Soulayrol, R., and Pinsard, N. (1964). L'encéphalopathie myoclonique infantile avec hypsarhythmie. Paris, Masson.

Gibbs, F. A., and Gibbs, E. L. (1952). Atlas of Electroencephalography, vol. 2. Cambridge, Mass., Addison-Wesley.

Gibbs, F. A., Gibbs, E. L., and Fleming, M. M. (1954). Pediatrics, 13, 66 Hess, R., and Neuhaus, T. (1952). Archiv für Psychiatrie und Nervenkrankheiten, vereinigt mit Zeitschrift für die gesamte Neurologie und Psychiatrie, $189,37$.

Jeavons, P. M., and Bower, B. D. (1964). In Clinics in Developmental Medicine, No. 15.

Jeavons, P. M., Harper, J. R., and Bower, B. D. (1970). Developmental Medicine and Child Neurology, 12, 413.

Lombroso, C. T., and Rose, A. (1964). Electroencephalography and Clinical Neurophysiology, 17, 464.

Pampiglione, G. (1956). Proceedings of the Electro-physiologists Technologists Association, 7, 20

Rebufat-Deschamps, M. (1958). Thesis quoted by Jeavons and Bower (1964).

Registrar General (1970). Statistical Review for England and Wales, 1968. London, H.M.S.O

Samson-Dollfus, D. (1959). Electroencephalography and Clinical Neurophysiology, 11, 578 .

Sorel, L., and Dusaucy-Bauloye, A. (1958). Acta neurologica et psychiatrica Belgica, 58, 130 .

\title{
Diagnosis of Established Deep Vein Thrombosis with the 125I Fibrinogen Uptake Test
}

\author{
N. L. BROWSE, W. F. CLAPHAM, \\ J. OLWEN WILLIAMS \\ D. N. CROFT, \\ D. J. JONES, M. LEA THOMAS,
}

British Medical fournal, 1971, 4, 325-328

\section{Summary}

One hundred and two patients with clinical signs indicating a possible diagnosis of deep vein thrombosis were studied with the fibrinogen uptake test and phlebography to assess the reliability of the test as a means of diagnosing established venous thrombosis. The test gave a correct diagnosis in $\mathbf{7 8} \%$ of the 85 legs shown to contain thrombus by phlebography and only $19(10 \%)$ falsenegative results in the 195 legs examined. The duration of the symptoms, the administration of anticoagulants, and mild leg swelling did not affect the accuracy of the test. Very old thrombus, phlebographically more than 11 days old, was associated with an increased falsenegative rate.

The fibrinogen uptake test is accurate enough to make it a valuable method of clinical investigation.

\section{Introduction}

Radioactive fibrinogen will be incorporated into a thrombus if it is circulating in the blood stream at the time that the thrombus

St. Thomas's Hospital, London S.E.1

N. L. BROWSE, M.D., F.R.c.s., Assistant Director, Surgical Unit

W. F. CLAPHAM, B.SC., Hospital Physicist

D. N. CROFT, D.M., M.R.C.P., Consultant Physician

D. J. JONES, M.B., B.S., M.R.C.P., Medical Registrar

M. LEA THOMAS, M.R.C.P., F.F.R., Consultant Radiologist

J. OLWEN WILLIAMS, M.B., B.S., M.R.C.P., Medical Registrar

forms. The thrombus will then have a high concentration of radioactivity which can be detected by external scintillation counting. This method for detecting deep vein thrombosis was first suggested by Hobbs and Davies (1960) on the basis of experiments in the rabbit. Their work was not followed up with any enthusiasm until Atkins and Hawkins (1965), Nanson et al. (1965), Flanc et al. (1968), and Negus et al. (1968) simplified the method by using the longer-lasting isotope of iodine, ${ }^{125} \mathrm{I}$, in place of ${ }^{131} \mathrm{I}$, and proved its reliability in patients after surgical operations by comparing it with phlebography.

We have been more interested in the value of the ${ }^{125} \mathrm{I}$ fibrinogen uptake test as a means of diagnosing established deep leg vein thrombosis. Some of the workers already referred to mentioned the use of the test for this purpose but did not investigate this aspect in depth (see Discussion). We present our clinical experience with 102 patients who presented with symptoms or signs of either leg vein thrombosis or pulmonary embolism. Both the fibrinogen uptake test and ascending lower limb phlebography were performed in all patients. The results show that radioactive fibrinogen does accumulate in and around well-established thrombus to a degree that makes the technique a useful diagnostic method.

\section{Patients and Methods}

Each patient examined in this study was subjected to the investigation at the request of the clinician supervising his care because there was reason to think that the patient had a deep vein thrombosis or a pulmonary embolus. The patients had either some form of symptoms in the legs (pain, tenderness, Homans's sign, swelling of the ankle, dilated veins, or increased 